\title{
Is intravenous cholangiography an alternative to the routine per-operative cholangiogram?
}

\author{
Simon P.J. Huddy and John A. Southam \\ Epsom District Hospital, Dorking Road, Epsom, Surrey, UK
}

\begin{abstract}
Summary: Ultrasonography, although an accurate method of detecting stones within the gall bladder, is unreliable for the detection of bile duct stones for which per-operative cholangiography remains the standard investigation. Fifty seven patients undergoing elective cholecystectomy had both a pre-operative intravenous cholangiogram and per-operative cholangiography. The pre-operative investigation is shown to be at least as effective in the detection of common bile duct stones and only missed a duct stone in one patient. The substitution of pre-operative intravenous cholangiography for routine per-operative cholangiography would result in a significant reduction in operating time, may provide advance knowledge on the biliary anatomy and would allow advance planning of the likely procedure. It is suggested that pre-operative intravenous cholangiography, carried out on the day of admission, should be considered as a preferred alternative investigation to per-operative cholangiography.
\end{abstract}

\section{Introduction}

Per-operative cholangiography, first introduced by Mirizzi in $1932,{ }^{1}$ is now a commonly performed procedure. It is considered by many authorities to be an investigation which should be routinely performed at the time of cholecystectomy in order to identify those patients who have stones within the common bile duct. ${ }^{2-5}$ In the past, intravenous cholangiography has been considered to be both unreliable and to have an unacceptable complication rate. ${ }^{6,7}$ Recently, however, the introduction of improved and safer contrast media has prompted a reappraisal of the place of this investigation in patients with gall stones.

\section{Methods}

Fifty seven patients who underwent cholecystectomy under the care of a single surgeon (JAS) during a 42-month period from March 1984 were included in the study. They had both a pre-operative intravenous and a per-operative cholangiogram.

Ultrasound examination was the standard preoperative investigation of the gall bladder, although this examination was not ordered if the patient had already undergone an oral cholecystogram prior to referral. The ultrasound examinations were performed in the standard fashion on a Siemens RA 1 real time scanner using a $3.5 \mathrm{MHz}$ probe.

Correspondence: S.P.J. Huddy M Chir, F.R.C.S., Basingstoke District Hospital, Park Prewett, Basingstoke, Hants RG24 9LZ, UK.

Accepted: 1 June 1989
An intravenous cholangiogram was performed as an outpatient procedure before admission for cholecystectomy. A control film was taken prior to infusion of $100 \mathrm{ml}$ of meglumine iodoxamate (Endobil, E. Merck Ltd.) over 20-30 minutes. A single plain film was taken of the right upper abdomen and tomography routinely performed. Patients with a history of iodine allergy did not undergo this investigation.

Per-operative cholangiography was performed by injection of $10-20 \mathrm{ml}$ of $25 \%$ sodium diatrizoate (Hypaque, Sterling Research Laboratories) through a Stoke on Trent cannula placed in the common bile duct via the cystic duct. The patient was screened using an image intensifier during injection of contrast and films were taken after infusion of 2,5 and sometimes $20 \mathrm{ml}$ of contrast in order to have a permanent record of the investigation.

The pre-operative investigations were reported by consultant radiologists but the per-operative cholangiograms were assessed by the surgeon performing the operation and recorded in the operation notes made at the time. In this study the findings of the pre-operative intravenous cholangiogram are compared to those of an operative cholangiogram and the findings on exploration of the bile duct if performed. Each patient acted as their own control.

\section{Results}

The bile duct was investigated by both pre-operative intravenous cholangiography and per-operative

(C) The Fellowship of Postgraduate Medicine, 1989 
cholangiography in 57 patients. There were 22 males and 35 females. The mean age was 58 (range 24-90) years. The common bile duct was explored in $12(21 \%)$ and stones found within it in $8(14 \%)$.

The result of the two investigations were in agreement in 51 cases $(89 \%)$. The results are summarized in Table I. There was a mean delay of 91 days (range 1-272 days) between the pre-operative investigation and surgery.

Of the 6 patients in whom the investigations differed 2 patients had an abnormal pre-operative investigation but a normal operative cholangiogram and did not have the duct explored. It is therefore not possible to determine which of the investigations was correct. Neither of these patients has had recurrent symptoms. The remaining 4 patients in whom the two investigations differed proceeded to exploration of the duct. In 2 of these the intravenous investigation showed a normal duct but operative cholangiogram suggested the presence of stones resulting in exploration, but no stones were found. In a third patient no stone was detected on the pre-operative cholangiogram although the duct was noted to be dilated, the operative X-ray suggested a stone but again none was found on exploration. In the fourth case the intravenous investigation suggested a normal duct but a per-operative cholangiogram demonstrated stones which were found at exploration.

No patient was clincally jaundiced at the time of cholecystectomy. Thirteen patients had a history of clinical jaundice of whom 4 subsequently had their bile duct explored and were found to have an intraduct stone. Three underwent a negative duct exploration on the basis of either the pre-operative intravenous cholangiogram or the per-operative cholangiogram.

Table I Summary of the radiographic findings and the results of bile duct exploration in the patients who had both a pre-operative intravenous cholangiogram and a peroperative cholangiogram.

\begin{tabular}{lccc}
\hline & $\begin{array}{c}\text { Number } \\
\text { of patients }\end{array}$ & $\begin{array}{c}\text { Number } \\
\text { stones } \\
\text { seen/found }\end{array}$ & $\begin{array}{c}\text { Number } \\
\text { stones not } \\
\text { seen/found }\end{array}$ \\
\hline $\begin{array}{l}\text { Pre-operative } \\
\text { intravenous } \\
\text { cholangiogram }\end{array}$ & 57 & 10 & 47 \\
$\begin{array}{l}\text { Per-operative } \\
\text { cholangiogram }\end{array}$ & 57 & 11 & 46 \\
$\begin{array}{l}\text { Bile ducts } \\
\text { explored }\end{array}$ & 12 & 8 & $4 *$ \\
\hline
\end{tabular}

*Two -ve intravenous cholangiogram, + ve per-operative cholangiogram; one + ve intravenous cholangiogram, - ve per-operative cholangiogram; one dilated ducts on intravenous cholangiogram, + ve per-operative cholangiogram
Sixteen patients had abnormal liver function tests at some time. Four of these had their common bile duct explored and were found to have duct stones. Another 4 patients underwent a negative duct exploration.

Ten patients had a common bile duct which was considered by the surgeon to be dilated. Five of these were found on exploration to contain stones. Three further ducts were explored on the basis of a cholangiogram and no stones were found. The remaining two ducts were not explored.

In a separate group of 83 patients who underwent both a pre-operative ultrasound examination and a per-operative cholangiogram, 10 had stones demonstrated within the common bile duct by the operative $\mathrm{X}$-ray and confirmed by exploration of the duct. Only one of these duct stones was correctly predicted by the ultrasound scan, in the remaining 9 the duct was said to be of a normal calibre and no intraduct stones were identified.

\section{Discussion}

There have been a number of studies which have suggested that pre-operative intravenous cholangiography might be a suitable alternative to an operation cholangiogram ${ }^{8.9}$ but despite this, operative cholangiogram remains the most commonly performed investigation of the bile ducts.

Ultrasound, which reliably predicts the presence of stones within the gall bladder, cannot be relied upon to demonstrate the presence of stones within the bile ducts. ${ }^{10}$ This was confirmed in our group of 83 patients who underwent both ultrasound examination and a per-operative cholangiogram. Conversely, intravenous cholangiography has proved to be at least as reliable as the current standard investigation, peroperative cholangiography, and in this series would have only missed one common duct stone amongst 57 patients. In addition, exploration of the common bile duct would have been avoided in two patients who had a normal intravenous cholangiogram but an abnormal per-operative investigation and in whom no abnormality was found on exploration.

Definitive pre-operative investigation of the bile ducts will reduce the length of the operation. An operative cholangiogram will add at least 10 minutes to the operating time although in practice this is often much longer as repeat films may be required in order to adequately demonstrate the biliary tree or there may a delay in the arrival of the radiographer. Alinder et $a .^{8}$ showed a 17 minute reduction in the mean operating time when operative cholangiogram was performed selectively on those patients in whom the pre-operative $\mathrm{X}$-ray was inconclusive. The preoperative intravenous procedure involves the patient attending the X-ray department for approximately 
one hour and this would ideally be performed on the day of admission to hospital for surgery. During that time a radiographer and an X-ray room are required for approximately $\mathbf{5 0}$ minutes. A radiologist needs to be in the department to supervise the infusion and to monitor the films produced but will be able to attend to other matters at the same time. Only about 10 minutes of his time will actually be devoted to the investigation and this is comparable to an intravenous urogram.

An additional bonus of the pre-operative investigation is the delineation of the biliary anatomy and possible demonstration of any unusual situation. Although the quality of films obtained by intravenous cholangiography is inferior to those produced at operation, they have proved to be adequate to reliably predict duct stones and to demonstrate the major biliary anatomy. Alinder $e t a l .^{8}$ reported that the only major anatomical abnormality in their series was correctly predicted by pre-operative intravenous cholangiography.

The pre-operative intravenous cholangiogram does not preclude the subsequent performance of a peroperative investigation in those cases where the findings are inconclusive. In this respect the two investigations would complement each other although the number of occasions where this is necessary is likely to be small. In our series 3 intravenous cholangiograms were described as being poor studies and such patients would undergo a per-operative cholangiogram. Other series have reported an equivocal intravenous cholangiogram rate of about $10 \% .^{8.11}$

The third advantage of an intravenous cholangiogram is that the films are available prior to surgery. This improves planning of operating lists and allows the patient to be informed in advance of the procedure planned and how long they are likely to be in hospital. After a pre-operative investigation the films are reported and if there is any doubt the surgeon and radiologist may discuss the films together.

Intravenous cholangiography is an investigation which has been sparingly used in the past. This is largely due to the reputation of the earlier contrast media for producing allergic reactions. In this series of 57 investigations there were no adverse reactions noted. This confirms the experience of other investigators. Daly et al. ${ }^{9}$ reported no serious allergic reactions to the contrast (Endobil or Biliscopin) in $\mathbf{3 0 0}$ investigations over a period of 6 years and Alinder $e t$ $a l .{ }^{8}$ reported two major reactions in 200 investigations. In their paper they discuss the safety of modern contrast media. Of course, patients who have a history of allergy to iodine-containing contrast media should not undergo the investigation.

In our group of patients the intravenous cholangiogram was booked when the patient was first seen in the outpatient clinic and was carried out prior to admission for surgery. There was, therefore, a period (range 1-272, mean 91 days) after the investigation during which it was possible for stones either to migrate from the gall bladder into the bile ducts producing a false negative result (of which there was one in this series) or for stones which had previously been seen in the common bile duct to pass spontaneously, producing a false positive result. It is, however, interesting to note the remarkably few instances in which stones appear to have migrated from the gall bladder into the bile ducts despite the long interval between investigation and surgery and this has also been noted previously. "If intravenous cholangiography is to be adopted as the prime investigation to demonstrate duct stones then it should be performed as close as possible to the time of surgery. Ideally this should be on the day of admission for cholecystectomy which would also have the advantage of saving the patient an extra visit to hospital.

On the basis of the findings of this study it is suggested that pre-operative intravenous cholangiography be performed routinely and that per-operative investigation need only performed selectively in those few instances where doubt remains. Ultrasonography is not an effective investigation in this situation.

\section{References}

1. Mirizzi, P.L. Cholangiographic durante les operaciones de las vias biliares. Bal Trab Soc Cir Buenos Aires 1932, 16: 1133 .

2. Wheeler, M.H., Raksasook, S. \& Williams, J.A. Operative cholangiography: its effect on the practice of cholecystectomy. Br Med J 1970, 7: 161.

3. Argor, S. \& Schneider, H. The major role of the operative cholangiogram within the indications for common bile duct exploration. Am Surg 1984, 50: 530-533.

4. Kakos, G.S., Tompkins, R.K., Turnipseed, W. \& Zollinger, R.M. Operative cholangiography during routine cholecystectomy-a review of 3,012 cases. Arch Surg 1972, 104: 484-488.

5. Holliday, H.J., Farringer, J.L., Terry, R.B. \& Pickens, D.R. Operative cholangiography. Am J Surg 1980, 139: 379-382.

6. Goodman, M.W., Ansel, H.J., Vennes, J.A., Lasser, R.B. \& Silvis, S.E. Is intravenous cholangiography still useful? Gastroenterology 1980, 79: 642-645.

7. Scholz, F.J., Larsen, C.R. \& Wise, R.E. Intravenous cholangiography: recurring concepts. Semin Roentgenol 1976, 11: 197-202.

8. Alinder, G., Nilsson, U., Lunderquist, A., Herlin, P. \& Holmin, T. Pre-operative infusion cholangiography compared to routine operative cholangiography at elective cholecystectomy. Br J Surg 1986, 73: 383-387. 
9. Daly, J., Fitzgerald, T. \& Simpson, C.J. Pre-operative intravenous cholangiography as an alternative to routine operative cholangiography in elective cholecystectomy. Clin Radiol 1987, 38: 161-163.

10. Einstein, D.M., Lapin, S.A., Ralls, J.M. \& Halls, J.M. The insensitivity of sonography in the detection of choledocholithiasis. Am J Radiol 1984, 142: 725-728.
11. Goransson, G. Cholegraphy. Its application and reliability in connection with gallstone operations. A follow up study of 534 patients operated on because of cholelithiasis. Acta Chir Scand 1980, 496 (Suppl): 1-95. 